\title{
Structural Study of Wheat Gliadin in Different Solvents by Spectroscopic Techniques
}

\author{
Andresa C. Ribeiro, ${ }^{a}$ Daiani C. Leite, ${ }^{a}$ Jóice M. Scheibel, ${ }^{b}$ Rosane M. D. Soares ${ }^{b}$ and \\ Nádya P. Silveira ${ }^{\circledR *, a}$ \\ ${ }^{a}$ Laboratório de Bio\&Macromolecules, Instituto de Química, \\ Universidade Federal do Rio Grande do Sul, 91501-970 Porto Alegre-RS, Brazil \\ ${ }^{b}$ Grupo de Estudos em Biomateriais Poliméricos (POLI-BIO), Instituto de Química, \\ Universidade Federal do Rio Grande do Sul, 91501-970 Porto Alegre-RS, Brazil
}

\begin{abstract}
Physicochemical properties of gliadin in different solvents (dimethyl sulfoxide (DMSO), $\mathrm{H}_{2} \mathrm{O}$, and aqueous ethanol) and $\mathrm{pH}(9.8,6.8$, and 1.2) were investigated using dynamic light scattering (DLS), zeta potential (ZP), and attenuated total reflectance Fourier transform infrared spectroscopy (ATR-FTIR). Gliadin-DMSO and gliadin-deionized water $\left(\mathrm{H}_{2} \mathrm{O}\right)(\mathrm{pH} 9.8)$ showed a lower size distribution, whereas samples solubilized in $60 \%$ aqueous ethanol presented a lower size distribution only at $\mathrm{pH}$ 1.2. ZP analysis showed that gliadin $-\mathrm{H}_{2} \mathrm{O}(\mathrm{pH} 9.8)$ was the most stable evaluated system. $\mathrm{ZP}$ results of gliadin-DMSO indicated an unstable system, with the coexistence of several protein conformations. ATR-FTIR analysis showed that, in $\mathrm{H}_{2} \mathrm{O}$, most protein conformations were $\beta$-sheets, while in DMSO a band at $1660 \mathrm{~cm}^{-1}$ appeared to be related to protein unfolding. The techniques proved to be effective in monitoring conformation and stability of all gliadin/solvent systems. Such information can be used in the development of new gliadin-based materials.
\end{abstract}

Keywords: gliadin, spectroscopy, morphology, stability, biotechnology

\section{Introduction}

Gliadins are gluten proteins and their functionality has been a long-standing topic of investigation..$^{1-4}$ These proteins, together with glutenins, contribute about 80 $85 \%$ of the total protein in wheat grains. ${ }^{3,5,6}$ Hydrated gliadin confers the viscosity and extensibility of gluten, ${ }^{7-11}$ while hydrated glutenin is both cohesive and elastic and contributes to elasticity and strength of the gluten. ${ }^{8,9}$ Gliadins represent up to $40 \%$ of wheat proteins. ${ }^{11}$

Gliadins are heterogeneous mixtures of monomeric proteins, ${ }^{2}$ with molecular weights $\left(\mathrm{M}_{\mathrm{w}}\right)$ ranging from 30 to $50 \mathrm{kDa} .^{12}$ They have been traditionally divided into three fractions based on their electrophoretic mobility at low $\mathrm{pH}$, known as $\alpha$-, $\gamma$ - and $\omega$-gliadins. ${ }^{13-15}$ Another classification of gliadin is based on an amino acid sequence analysis, named sulfur-rich $(\alpha-, \gamma-)$ or poorprolamins $(\omega-) .{ }^{16}$ Furthermore, distribution of gliadins varies depending on the wheat source as well as growing conditions. Generally, $\alpha$ - and $\gamma$-gliadins are the major components of gliadin, whereas $\omega$-gliadins are found in lower amounts. ${ }^{14}$ Moreover, $\alpha$ - and $\gamma$-gliadins contain

*e-mail: nadya@iq.ufrgs.br intrachain disulfide bonds while $\omega$-gliadin lacks cysteine residues. ${ }^{17,18}$

The gliadin secondary structure comprises a nonrepetitive domain rich in $\alpha$-helix and repetitive domains rich in reverse or $\beta$-turns ${ }^{17,19}$ (in $\alpha$ - and $\gamma$-gliadins). Thus, gliadin presents an overall compact globular structure..$^{20}$ The $\omega$-gliadins also contain $\beta$-turns but only low levels of $\alpha$-helices and $\beta$-sheets. However, it was later found that, although $\alpha$-gliadins have a compact and less regular structure, $\gamma$-gliadins rather form an extended-spiral tertiary structure. The $\omega$-gliadins presumably adopt a stiff coil rather than a compact structure. ${ }^{17}$

Over the last decade, there were considerable advances in methodologies for the analysis of biopolymers in solution. It is known, for example, that many proteins in solution occur naturally and perform their biological functions. ${ }^{21,22}$ However, theoretical arguments and experimental studies suggest that interactions between such biomacromolecules and the solvent, depending on $\mathrm{pH}$, may lead to a re-structuring of the material. ${ }^{23}$ This fact can lead to an increase in the particle size through aggregation. On the other hand, the interaction strength between the molecules can facilitate a decrease in particle size, producing folding on itself. ${ }^{24}$ 
Gliadin has unique biochemical and physical properties, which enable numerous non-food applications, ${ }^{25,26}$ such as in edible films, manufacture of packaging, preparation of nanoparticles for drug controlled release, among others. ${ }^{25,27}$ Therefore, the study of the molecular conformation, intermolecular interaction and protein behavior in different solvents and $\mathrm{pH}$ seem to provide valuable information for understanding the end-use functionalities of gliadins. ${ }^{28}$

The proteins tend to adopt a structure that minimizes the overall free energy of the system. There are no kinetic constraints (energy barriers) that prevent them from reaching this low energy state, and their morphology depends on its amino acid sequence, density, refractive index, size, charge, stability environmental conditions, pressure, solvents, $\mathrm{pH}$, and ionic strength. So, it is important to understand the physical properties of proteins. These factors will determine rheological properties, stability properties of proteins as a potential biomaterial, and functional properties of proteins as a potential biomaterial. ${ }^{29}$

Thereby, in the present study we used dynamic light scattering (DLS), zeta potential (ZP), and attenuated total reflectance Fourier transform infrared spectroscopy (ATR-FTIR) techniques to investigate native gliadin conformations in three different solvents: $\mathrm{H}_{2} \mathrm{O}$, dimethyl sulfoxide (DMSO) and 60\% (v/v) aqueous ethanol. The samples were characterized at pH 9.8 (gliadin dissolution) and at human physiological pHs 1.2 and 6.8, corresponding to gastric and intestinal pHs, respectively. ${ }^{30}$ The aim of the study in physiological $\mathrm{pH}$ is to obtain the mechanism of the gliadin interaction in the gastro-intestinal tract. Moreover, the study in different solvents is also important to evaluate new uses of gliadin in the food and pharmaceutical industries.

\section{Experimental}

\section{Materials}

Wheat gliadin samples (crude, a mixture of $\alpha$-, $\gamma$ - and $\omega$-) were purchased from Sigma-Aldrich ${ }^{\circledR}$ (St. Louis, USA) and used without further purification. DMSO, ethanol, hydrochloric acid $(\mathrm{HCl})$ and sodium hydroxide $(\mathrm{NaOH})$ were purchased from Fischer Scientific (Waltham, USA).

\section{Methods}

\section{Sample preparation}

Three different solvents were employed to dissolve the gliadin: deionized $\mathrm{H}_{2} \mathrm{O}$, DMSO and $60 \%$ (v/v) aqueous ethanol. Samples were characterized at $\mathrm{pH}$ (9.8) and at physiological pHs: 1.2 (gastric) and 6.8 (intestinal).
Gliadin concentration was based on the corresponding analysis technique: $100 \mathrm{mg} \mathrm{L}^{-1}$ for DLS and ZP analysis and $100 \mathrm{~g} \mathrm{~L}^{-1}$ for ATR-FTIR analysis.

The solutions were kept under magnetic stirring for $36 \mathrm{~h}$ (for samples in DMSO) and $24 \mathrm{~h}$ (for samples in $60 \%$ (v/v) aqueous ethanol and deionized $\mathrm{H}_{2} \mathrm{O}$ ), at $50{ }^{\circ} \mathrm{C}$ and $\mathrm{pH} 9.8$. After solubilization, the solution $\mathrm{pH}$ was adjusted to 6.8 (intestinal) and 1.2 (gastric) with $1 \mathrm{~mol} \mathrm{~L}^{-1} \mathrm{HCl}$.

\section{Dynamic light scattering (DLS)}

The DLS experiments were performed using a Brookhaven Instruments spectrometer (USA) (BI200M goniometer, BIC 9000AT digital correlator) with a vertically polarized coherent He-Ne laser $(\lambda=632.8 \mathrm{~nm})$ as light source. The time-dependence autocorrelation function was obtained using a multi- $\tau$ mode correlator with 224 channels. DLS measures a time profile of the normalized autocorrelation function of the light intensity, $g_{2}(\tau)$, which is related to the electric field normalized correlation function, $g_{1}(\tau)$, through the Siergert relation ${ }^{31} g_{2}(\tau)=B+\beta\left[g_{1}(\tau)\right]^{2}$, where $\tau$ is the time delay, $\beta$ is the coherent factor depending on the detection optics, ${ }^{31}$ and $\mathrm{B}$ is the measured baseline. ${ }^{32}$ For a polydisperse sample,,$^{33} \mathrm{~g}_{1}(\tau)$ is expressed as a sum or an integral over a distribution of decay rates $G(\Gamma)$ by: $g_{1}(\tau)=\int_{0}^{\infty} \mathrm{G}(\Gamma) \exp (-\Gamma \mathrm{t}) \mathrm{d} \Gamma$, where $\Gamma$ is the relaxation rate. ${ }^{34}$ Two types of analysis of the correlation functions were used, inverse Laplace transformation using the CONTIN algorithm and the cumulants method as will be further discussed in the text. The decay rates $(\Gamma)$ are proportional to $\mathrm{q}^{2}, \mathrm{D}=\Gamma / \mathrm{q}^{2}$, where $\mathrm{D}$ is the translational diffusion coefficient. The magnitude of the scattering vector $q$ is given by: $q=4 \pi n / \lambda_{0} \sin (\theta / 2)$, where $n$ is the solvent refractive index, $\mathrm{q}$ the scattering vector, $\theta$ is the scattering angle and $\lambda_{0}$ the laser wavelength in vacuum. ${ }^{31,35}$ The hydrodynamic radius $\mathrm{R}_{\mathrm{h}}$ (or hydrodynamic size, $\mathrm{D}_{\mathrm{h}}$ ) was obtained via the Stokes-Einstein equation: $R_{h}=k_{B} T / 6 \pi \eta D$, where $\mathrm{k}_{\mathrm{B}}$, $\mathrm{T}$, and $\eta$ are the Boltzmann constant, the absolute temperature and the solvent viscosity, respectively. ${ }^{31,32}$

Polydispersity index (PD.I) was calculated using the cumulants method. PD.I describes the amplitude of the size distribution and was calculated according to equation: PD.I $=\mu_{2} /\langle\Gamma\rangle^{2}$, where $\mu_{2}$ is the variance of distribution. ${ }^{35,36}$ The scattered light was analyzed after placing the sample into dust free cuvettes which were placed in the indexmatching liquid decahydronaphtalene (Aldrich, St. Louis, USA). All measurements were made in duplicate at $24^{\circ} \mathrm{C}$ and at a $90^{\circ}$ scattering angle.

\section{Zeta potential (ZP)}

The ZP was measured by microelectrophoresis with a Brookhaven Instrument's ZetaPlus (USA) (software 
ZetaPals). The ZP was calculated using the Smoluchowski equation from the electrophoresis mobility and electric field strength. ZP was determined at different solution $\mathrm{pH}$. The value was recorded as the average of five measurements and the values reported are the mean \pm standard deviation at room temperature.

Attenuated total reflectance Fourier transform infrared spectroscopy (ATR-FTIR)

For the ATR-FTIR experiments, the samples in solution were cast onto Petri dishes and thin films were obtained. ATR-FTIR spectra at a nominal resolution of $4 \mathrm{~cm}^{-1}$ were recorded on Bruker Alpha-P Model of Module ATR with diamond prism (USA). For the secondary structure studies of the gliadin, the spectra were analyzed by second derivatization and Gaussian curve fitting in the amide I region $\left(1600-1700 \mathrm{~cm}^{-1}\right)^{37}$ using Origin software. ${ }^{38}$ The secondary structural content was calculated from the relative areas of the individual assigned bands in the amide I region. The relative areas of the components were expressed as a percentage of the area of each fitted region, which was equivalent to an area normalization of the amide I band. ${ }^{39}$ All experiments were performed in quadruplicate at room temperature.

\section{Results and Discussion}

\section{Analysis of gliadin conformation by DLS and ATR-FTIR}

Figure 1a shows the autocorrelation functions measured at scattering angle of $90^{\circ}$. A large decay rate was observed for all solvents. However, samples in DMSO presented a distinct autocorrelation function when compared to samples dissolved in water and aqueous ethanol. In DMSO,

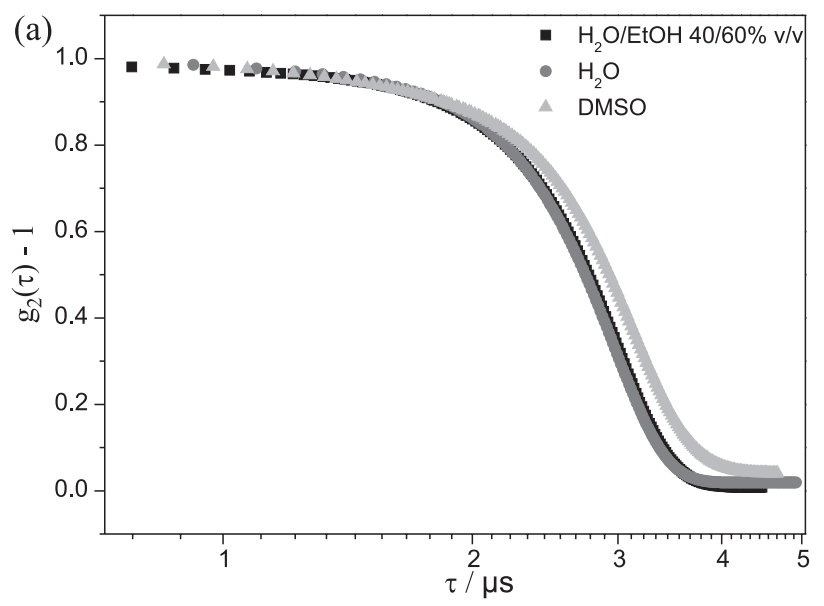

the results obtained in DLS experiments showed a wide monomodal Gaussian distribution (Figure 1b), suggesting the existence of different aggregation structures.

To prove this hypothesis, polydispersity index (PD.I) measurements were also made (Table 1). The values found for sample in DMSO were slightly above 0.3 indicating a Gaussian distribution, and a high sample heterogeneity. ${ }^{40}$ It is suggested that this fact is due to the sample homogenization which also affects the PD.I and this result may also indicate that in this solvent the gliadin stays in an unfolded conformation. Similar properties were also observed for the lysozyme protein (globular protein) in DMSO. ${ }^{41}$

Table 1. Influence of $\mathrm{pH}$ and solvent on the polydispersity index (PD.I) and, diffusion coefficient (D) of gliadin

\begin{tabular}{lccc}
\hline Solvent & $\mathrm{pH}$ & PD.I & $\mathrm{D} /\left(10^{-8} \mathrm{~cm}^{2} \mathrm{~s}^{-1}\right)$ \\
\hline \multirow{3}{*}{ DMSO } & 1.2 & $0.37 \pm 0.01$ & $3.30 \pm 0.14$ \\
& 6.8 & $0.37 \pm 0.13$ & $5.37 \pm 1.21$ \\
& 9.8 & $0.40 \pm 0.09$ & $6.41 \pm 0.57$ \\
\hline \multirow{2}{*}{$\mathrm{H}_{2} \mathrm{O}$} & 1.2 & $0.27 \pm 0.07$ & $2.98 \pm 0.37$ \\
& 6.8 & $0.15 \pm 0.12$ & $1.98 \pm 0.56$ \\
& 9.8 & $0.28 \pm 0.02$ & $7.18 \pm 0.03$ \\
60\% (v/v) & 1.2 & $0.24 \pm 0.04$ & $5.57 \pm 1.40$ \\
aqueous ethanol & 6.8 & $0.19 \pm 0.07$ & $3.40 \pm 0.51$ \\
& 9.8 & $0.26 \pm 0.02$ & $5.10 \pm 0.40$ \\
\hline
\end{tabular}

DMSO: dimethyl sulfoxide.

For samples in water and aqueous ethanol bimodal particle size distribution curves were observed (Figure 1b). It was suggested that the populations will be formed of monomers and dimers with slightly bigger sizes than those expected, due to the relaxation of the global protein

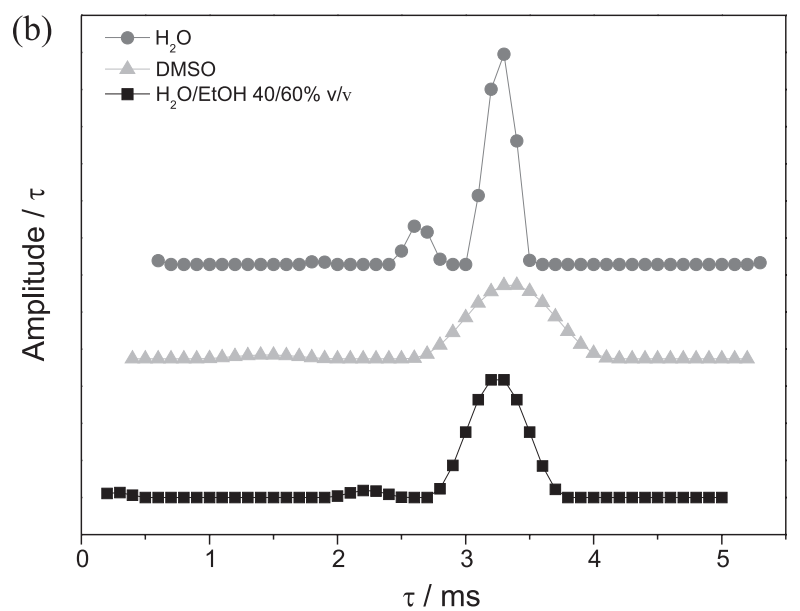

Figure 1. (a) Normalized intensity autocorrelation function $\mathrm{g}_{2}(\mathrm{t})$, plotted as a function of delay time; (b) relaxation time distribution of gliadin in $\mathrm{H}_{2} \mathrm{O}$, $60 \%(\mathrm{v} / \mathrm{v})$ aqueous ethanol, and DMSO; scattering angle $=90^{\circ} ; \mathrm{pH}=9.8$; temperature, $24{ }^{\circ} \mathrm{C}$, measured by DLS. The values are expressed as mean of three experiments. 
structure. It was suggested that this might be due to an increase in the random structure and a decrease in $\alpha$ helical structures.

The diffusion coefficients (D) are also shown in Table 1. It can be observed that diffusion coefficients were higher for samples in DMSO and deionized water, at $\mathrm{pH} 9.8$. According to Stokes-Einstein equation the diffusion coefficient is inversely proportional to hydrodynamic size. ${ }^{31}$ Meaning that as the gliadin diffusion coefficient increases, the hydrodynamic size decreases. Thus, gliadin chains can diffuse more easily in the solvent.

According to the increase of $\mathrm{pH}$, the folding states of gliadin goes from coil to an unfolded state, which means that in higher $\mathrm{pH}$ solution the gliadin-solvent interaction is enhanced, reflected in higher diffusion coefficients.

In order to confirm this behavior, ATR-FTIR analysis was also performed. According to literature ${ }^{42}$ the amide I band is used to determine the secondary structure of gluten proteins. Firstly, an intense band at $1660 \mathrm{~cm}^{-1}$ was observed in ATR-FTIR spectrum of gliadin in DMSO at pH 9.8 (data not shown), which indicates the predominance of $\beta$-turn structure. ${ }^{43}$ The major predominance of this structure can be due to the fact that DMSO has a strong acceptor group of hydrogen bond which can bind to $\mathrm{N}-\mathrm{H}$ groups, showing a higher stretching frequency. ${ }^{44}$ However, at $\mathrm{pH} 9.8$ there is also a band at $1629 \mathrm{~cm}^{-1}$. This band indicates a $\beta$-sheet structure which was assigned as aggregation or intermolecular hydrogen bonds. ${ }^{45}$ This result indicates that the polypeptide backbone of gliadin is accessible to DMSO, e.g., there are interactions between the solvent and side chains of gliadin. This fact was also observed in other studies. ${ }^{46,47}$

Investigation of the second derivative showed that the ATR-FTIR bands located at 1600-1609 and 1606-1611 cm-1 disappeared at pH 1.2 (Figure 2).

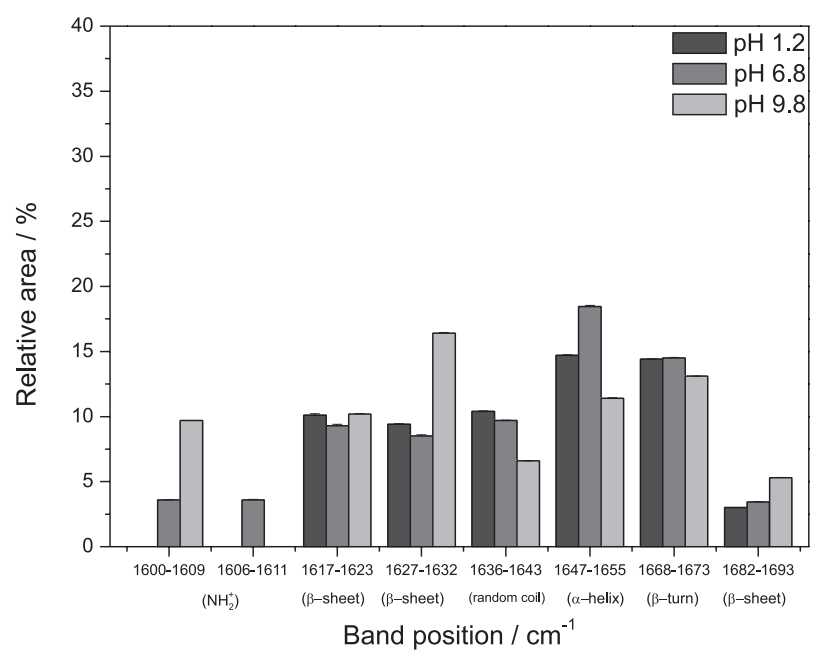

Figure 2. Positions and relative areas of the bands fitted to the Fourier deconvoluted spectra of gliadin in DMSO; temperature, $24{ }^{\circ} \mathrm{C}$.
These bands originated from the glutamine side chains ( $\mathrm{NH}_{2}$ scissoring band). ${ }^{48,49}$ The absence of these bands indicates that at acidic $\mathrm{pH}$, DMSO molecules interact with glutamine side-chain residues of the gliadin. At $\mathrm{pH}$ 1.2, the carboxylate groups on gliadin are deprotonated. This might increase the interaction between the protein and DMSO causing a decrease in the diffusion coefficient.

For samples diluted in water, some changes in the ATR-FTIR band at 1627-1632 $\mathrm{cm}^{-1}$ (Figure 3) were observed. This band is related to an extended $\beta$-sheet structure, ${ }^{50,51}$ characterized by an increase of protein-protein interaction. ${ }^{27,52}$

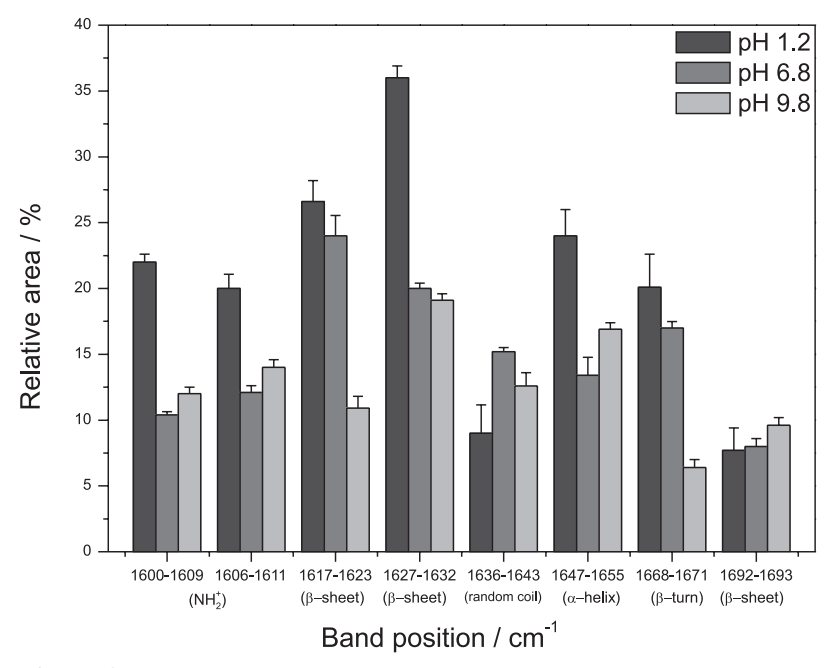

Figure 3. Positions and relative areas of the bands fitted to the Fourier deconvoluted spectra of gliadin in $\mathrm{H}_{2} \mathrm{O}$; temperature, $24{ }^{\circ} \mathrm{C}$.

At $\mathrm{pH}$ 1.2, the protonated and unfolded protein structure leads to closer contact among protein residues. This may be corroborated to the decrease of diffusion coefficients at low $\mathrm{pH}$. On the other hand, the results obtained for diffusion coefficient in $60 \%$ aqueous ethanol at $\mathrm{pH} 1.2$ and 9.8 were similar (Table 1) and shows that gliadin diffusion is easier under these conditions. In fact, the second derivative spectra of gliadin in this solvent (Figure 4) showed that at $\mathrm{pH} 6.8$ the secondary structure of gliadin contains $16 \%$ of a random coil and $18 \% \beta$-sheet structure.

As mentioned in other studies, ${ }^{53,54}$ these bands are related to aggregation processes which are accompanied by changes in conformation and/or structure of the protein. The increase of these bands can indicate denaturation or can reflect the disruption of hydrogen bonds within some secondary structure of gliadin and the formation of new, stronger hydrogen bonds, associated with aggregation, e.g., formation of intermolecular hydrogen bonds. ${ }^{54}$ Thus, the increase of the size of these structures are attributed to the increase of protein-protein interactions between different gliadin molecules. 


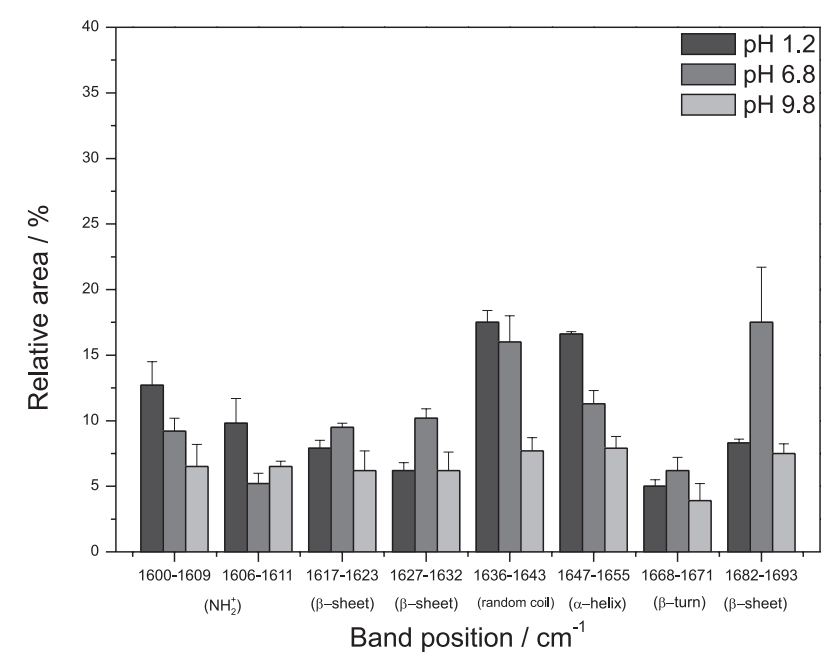

Figure 4. Positions and relative areas of the bands fitted to the Fourier deconvoluted spectra of gliadin in $60 \%$ (v/v) aqueous ethanol; temperature, $24{ }^{\circ} \mathrm{C}$.

Influence of $\mathrm{pH}$ and solvent on the hydrodynamic size $\left(D_{h}\right)$ and zeta potential (ZP) of gliadin

The average hydrodynamic sizes of gliadin in the different $\mathrm{pH}$ and solvents are shown in Figure 5. According to literature, ${ }^{55}$ the hydrodynamic size is highly affected by the protein molecule shape in solution.

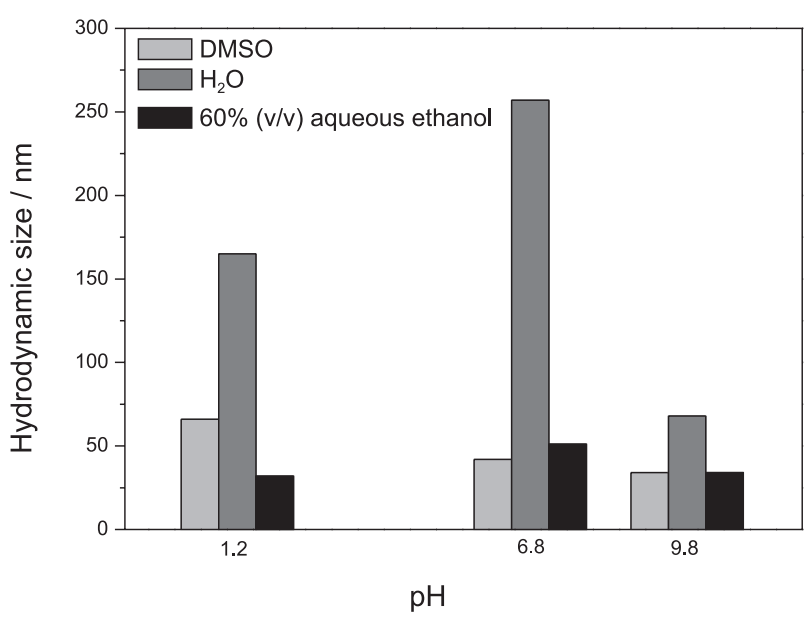

Figure 5. Hydrodynamic size for gliadin in $\mathrm{H}_{2} \mathrm{O}, 60 \%$ (v/v) aqueous ethanol, and DMSO solvents as a function of $\mathrm{pH}$.

Gliadin molecules in water, for example, existed as aggregates with hydrodynamic size higher than in other solvents of this study. These results are similar to those observed in another study ${ }^{56}$ for gliadin in aqueous solvents. Besides this, it was observed that in water the smallest hydrodynamic size of gliadin was obtained at pH 9.8 (Figure 5). In conclusion, when the $\mathrm{pH}$ increases, some changes on protonated groups through the peptide chains are expected. At $\mathrm{pH} 9.8$, the deprotonation of the amino and carboxylate groups occurred, decreasing the repulsive interaction forces and protein-protein interactions, which consequently decreased the size of the aggregates, resulting in a more folded molecular structure. On the other hand, the hydrodynamic size of gliadin is higher at pH 6.8 indicating that for this $\mathrm{pH}$, the gliadin molecules are unstable, presenting a tendency to unfold.

Measures of the gliadin hydrodynamic size in aqueous ethanol were also made (Figure 5). In fact, alcohols are known to stabilize helical secondary structures, as well as to destabilize tertiary structures of folded proteins. ${ }^{57,58}$ These effects may cause the formation of non-native conformations. A similar situation has been reported in human serum albumin ${ }^{59}$ and lysozyme ${ }^{60}$ (globular proteins). It is worth mention that the relation between $\mathrm{pH}$ and gliadin conformation in aqueous ethanol solution is not yet reported in the literature. The results showed that $\mathrm{pH} 6.8$ is able to destabilize the gliadin secondary structure, giving rise to an unfolding process of the protein. This process can increase the protein-protein interaction causing aggregation. In addition, the increase of attractive interactions over the hydrophobic interactions can be due to the proximity of the gliadin isoelectric point ( $\mathrm{pH}$ 6.8) ${ }^{61,62}$ Finally, hydrodynamic sizes of gliadin at $\mathrm{pH} 1.2$ and 9.8 are $32.0 \pm 8.3 \mathrm{~nm}$ and $34.0 \pm 2.6 \mathrm{~nm}$, respectively (Figure 5). Hence, at pHs 1.2 and 9.8, there is a decrease in repulsive interactions, resulting in a more folded protein structure.

ZP data corroborated these results (Figure 6). The $\mathrm{ZP}$ value measured at $\mathrm{pH} 9.8$ in water was $-26.6 \mathrm{mV}$. According to the literature, ${ }^{63}$ zeta potential values greater than $+30 \mathrm{mV}$ and lower than $-30 \mathrm{mV}$ produce systems that are stable over time. Thus, at $\mathrm{pH} 9.8$, it was suggested that the gliadin is charged with molecules that repel one another, thus overcoming the natural tendency to aggregate.

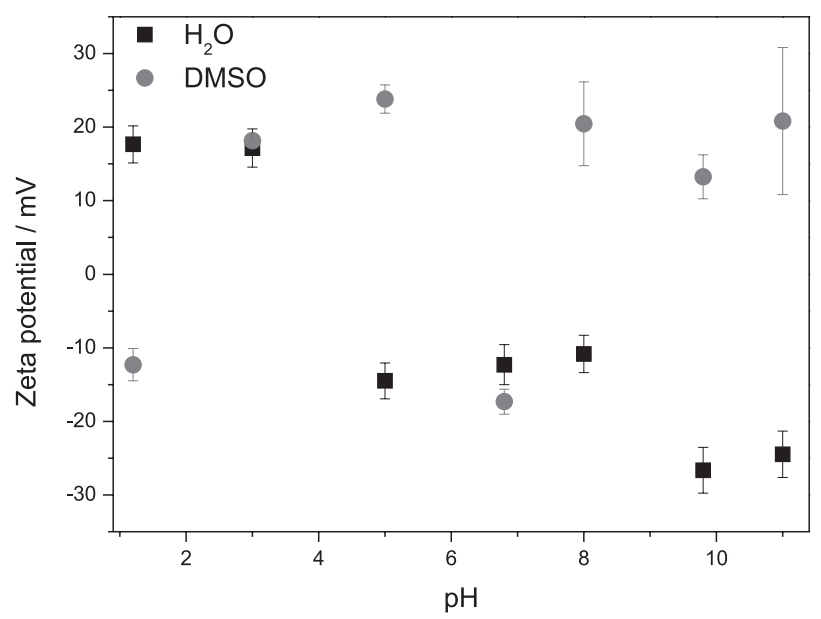

Figure 6. Zeta potential measurement as a function of $\mathrm{pH}$ for gliadin in $\mathrm{H}_{2} \mathrm{O}$ and DMSO; temperature, $24^{\circ} \mathrm{C}$. 
On the other hand, at $\mathrm{pH} 1.2$, the obtained value for zeta potential was $-17.7 \mathrm{mV}$. According to the literature, ${ }^{64}$ $\mathrm{pH} 1.2$ is far from the isoelectric point of gliadin ( $\mathrm{pH} 5.76$ ). At this $\mathrm{pH}$, carboxylate groups on gliadin are protonated $(-\mathrm{COOH})$ and the amine residues are ionized $\left(-\mathrm{NH}_{3}{ }^{+}\right)$. The repulsion between charges of the side chains with the $\mathrm{H}^{+}$ ions induces a partial unfolding of the protein, destabilizing the peptide-peptide interchain H-bonds. ${ }^{65}$ This behavior corroborates to the higher values of hydrodynamic size and zeta potential values at $\mathrm{pH} 1.2$.

For gliadin in DMSO, a typical behavior can be observed in Figure 5. It is well known that native folded structure and function of proteins are significantly affected by DMSO. ${ }^{66}$ This solvent can compete and disrupt many non-covalent interactions, e.g., hydrogen bond, salt-bridge formation and van der Waals interactions, which stabilize the protein structure. ${ }^{47}$

In this study, the DLS results for gliadin in DMSO showed compact structures with hydrodynamic sizes between $66 \mathrm{~nm}$ (at pH 1.2) and $34 \mathrm{~nm}(9.8 \mathrm{pH})$. In pH 9.8, carboxylate groups $(-\mathrm{COOH})$ are protonated and amine groups are ionized $\left(-\mathrm{NH}_{3}{ }^{+}\right)$. There is a positive liquid charge ( $\mathrm{ZP}=+13.26 \mathrm{mV}$ ). When the $\mathrm{pH}$ is lower (1.2), carboxylate groups are deprotonated $\left(-\mathrm{COO}^{-}\right)$and gliadin has a negative charge $(\mathrm{ZP}=-12.29 \mathrm{mV})$. This value is different from gliadin dissolved in $\mathrm{H}_{2} \mathrm{O}$, but in the same $\mathrm{pH}(+17.7 \mathrm{mV})$. Negative values of $\mathrm{ZP}$ indicated that the protein changed its conformation. It is suggested that, in $\mathrm{H}_{2} \mathrm{O}$, the hydrophobic residues are now exposed, and this conformation is considered partially collapsed.

The results showed that the ZP values for gliadin dissolved in $\mathrm{H}_{2} \mathrm{O}$ tend to decrease as the $\mathrm{pH}$ increases. Besides, gliadin is more stable when solubilized in water at $\mathrm{pH}$ 9.8. On the other hand, in DMSO, the ZP values are more unstable, varying from negative to positive value depending on $\mathrm{pH}$ range. We believe that high DMSO concentration turns the protein structure unstable once the non-polar lateral chain binds to DMSO. This was observed in other studies. ${ }^{67,68}$

\section{Conclusions}

The results reported here indicate that the polypeptide chain of gliadin can adopt a variety of conformations in response to solvent and $\mathrm{pH}$ changes. Light scattering measurements enabled several possible gliadin hydrodynamic sizes in solution. For samples in DMSO and $\mathrm{H}_{2} \mathrm{O}$, we can conclude that increase in $\mathrm{pH}$ caused a decrease in gliadin molecular size, while for samples solubilized in $60 \%$ aqueous ethanol smaller size was obtained at $\mathrm{pH}$ 1.2. Larger sizes obtained by DLS analysis can be related to aggregation of gliadin molecules. Although all solvents employed to dissolve gliadin are polar, the intermolecular forces may play a major role in ethanol, where the protein is more folded, when compared to its structure in other solvents. ATR-FTIR and ZP analysis confirmed the results obtained above. Our results demonstrated that spectroscopic techniques, employed together, were effective to monitor the gliadin chain conformation under different conditions.

\section{Acknowledgments}

The authors appreciate the financial assistance received from Coordination of Superior Level Staff Improvement (CAPES) and the National Synchrotron Light Laboratory (LNLS, Campinas, SP, Brazil).

\section{References}

1. Joye, I. J.; Nelis, V. A.; McClements, D. J.; Food Hydrocolloids 2015, 43, 236.

2. Wang, P.; Jin, Z.; Xu, X.; Trends Food Sci. Technol. 2015, 46, 189.

3. Wang, P.; Zou, M.; Liu, K.; Gu, Z.; Yang, R.; Food Chem. 2018, 239, 984

4. Sharif, N.; Golmakani, M.-T.; Niakousari, M.; Ghorani, B.; Lopez-Rubio, A.; Food Res. Int. 2019, 116, 1366.

5. Barak, S.; Mudgil, D.; Khatkar, B. S.; Crit. Rev. Food Sci. Nutr. 2015, 55, 357.

6. Biesiekierski, J. R.; J. Gastroenterol. Hepatol. 2017, $32,78$.

7. Taylor, J. R. N.; Taylor, J.; Campanella, O. H.; Hamaker, B. R.; J. Cereal Sci. 2016, 67, 22.

8. Majzoobi, M.; Abedi, E.; Farahnaky, A.; Aminlari, M.; Food Chem. 2012, 133, 1402.

9. Ortolan, F.; Corrêa, G. P.; da Cunha, R. L.; Steel, C. J.; LWTFood Sci. Technol. 2017, 79, 647.

10. Han, C.; Ma, M.; Li, M.; Sun, Q.; Food Hydrocolloids 2020, 103,105661 .

11. Lupi, R.; Denery-Papini, S.; Claude, M.; Tranquet, O.; Drouet, M.; Masci, S.; Larré, C.; Food Res. Int. 2019, 118, 22.

12. Diao, C.; Xia, H.; Parnas, R. S.; ACS Appl. Mater. Interfaces 2015, 7, 22601.

13. Shewry, P. R.; Tatham, A. S.; J. Cereal Sci. 2016, 67, 12.

14. Smith, F.; Pan, X.; Bellido, V.; Toole, G. A.; Gates, F. K.; Wickham, M. S. J.; Shewry, P. R.; Bakalis, S.; Padfield, P.; Mills, E. N. C.; Mol. Nutr. Food Res. 2015, 59, 2034.

15. García-Molina, M. D.; Muccilli, V.; Saletti, R.; Foti, S.; Masci, S.; Barro, F.; J. Proteomics 2017, 165, 102.

16. Dias, R.; Perez-Gregorio, M. R.; Mateus, N.; de Freitas, V.; Food Chem. 2016, 194, 1304.

17. Delcour, J. A.; Joye, I. J.; Pareyt, B.; Wilderjans, E.; Brijs, K.; Lagrain, B.; Annu. Rev. Food Sci. Technol. 2012, 3, 469. 
18. Sun, S.; Song, Y.; Zheng, Q.; Food Hydrocolloids 2008, 22, 1090.

19. Soares, R. M. D.; Lionzo, M. I.; da Silveira, N. P.; Rayas-Duarte, P.; Soldi, V.; Int. J. Biol. Macromol. 2012, 51, 640.

20. Khatkar, B. S.; Barak, S.; Mudgil, D.; Int. J. Biol. Macromol. 2013, 53, 38.

21. Banachowicz, E.; Biochim. Biophys. Acta, Proteins Proteomics 2006, 1764, 405.

22. Harding, S. E.; Abdelhameed, A. S.; Morris, G. A.; Polym. Int. 2011, 60, 2.

23. Tu, Y.; Luo, Y.; Ågren, H.; J. Phys. Chem. B 2005, 109, 16730.

24. Giacomelli, F. C.; da Silveira, N. P.; Stepanek, P.; Macromolecules 2009, 42, 3818.

25. Mohammadinejad, R.; Karimi, S.; Iravani, S.; Varma, R. S.; Green Chem. 2016, 18, 20.

26. Hong, N. V.; Pyka, G.; Wevers, M.; Goderis, B.; Van Puyvelde, P.; Verpoest, I.; Van Vuure, A. W.; Composites, Part A 2015, 79, 74.

27. Rahaman, T.; Vasiljevic, T.; Ramchandran, L.; Food Chem. 2016, 196, 180.

28. Zhang, Z.; Scanlon, M. G.; J. Cereal Sci. 2011, 54, 181.

29. Matalanis, A.; Jones, O. G.; McClements, D. J.; Food Hydrocolloids 2011, 25, 1865.

30. Gwak, G.-H.; Lee, W.-J.; Paek, S.-M.; Oh, J.-M.; Colloids Surf., B 2015, 127, 137.

31. Naiim, M.; Boualem, A.; Ferre, C.; Jabloun, M.; Jalocha, A.; Ravier, P.; Soft Matter 2015, 11, 28.

32. Othman, M.; Aschi, A.; Gharbi, A.; Mater. Sci. Eng., C 2016, $58,316$.

33. Frisken, B. J.; Appl. Opt. 2001, 40, 4087.

34. Kabir-ud-Din; Siddiqui, U. S.; Ghosh, G.; J. Dispersion Sci. Technol. 2009, 30, 1310.

35. Berne, B. J.; Pecora, R.; Dynamic Light Scattering with Applications to Chemistry, Biology, and Physics, $2^{\text {nd }}$ ed.; Dover Publications: New York, USA, 1977.

36. Peres, G. L.; Leite, D. C.; da Silveira, N. P.; Starch 2015, 67, 407.

37. Zhang, L.; Zhang, F.; Wang, X.; J. Food Eng. 2016, 171, 159.

38. OriginPro, version 9.5; OriginLab Corporation, USA, 2019.

39. Hesso, N.; Marti, A.; Le-Bail, P.; Loisel, C.; Chevallier, S.; Le-Bail, A.; Seetharaman, K.; Food Hydrocolloids 2015, 51, 101.

40. Maharana, T.; Mohanty, B.; Negi, Y. S.; Int. J. Green Nanotechnol. Phys. Chem. 2010, 2, P100.

41. Voets, I. K.; Cruz, W. A.; Moitzi, C.; Lindner, P.; Arêas, E. P. G.; Schurtenberger, P.; J. Phys. Chem. B 2010, 114, 11875.

42. Nawrocka, A.; Miś, A.; Niewiadomski, Z.; J. Cereal Sci. 2017, 74,86 .

43. Wang, K.; Luo, S.; Cai, J.; Sun, Q.; Zhao, Y.; Zhong, X.; Jiang, S.; Zheng, Z.; Food Chem. 2016, 197, 168.

44. Dzwolak, W.; Kalinowski, J.; Johannessen, C.; Babenko, V.; Zhang, G.; Keiderling, T. A.; J. Phys. Chem. B 2012, 116, 11863.
45. Ulrichs, T.; Drotleff, A. M.; Ternes, W.; Food Chem. 2015, 172, 909.

46. Jackson, M.; Mantsch, H. H.; Biochim. Biophys. Acta, Protein Struct. Mol. Enzymol. 1991, 1078, 231.

47. Liu, C.; Bo, A.; Cheng, G.; Lin, X.; Dong, S.; Biochim. Biophys. Acta, Protein Struct. Mol. Enzymol. 1998, 1385, 53.

48. Carbonaro, M.; Maselli, P.; Nucara, A.; Amino Acids 2012, 43, 911.

49. Mizutani, Y.; Matsumura, Y.; Imamura, K.; Nakanishi, K.; Mori, T.; J. Agric. Food Chem. 2003, 51, 229.

50. Gao, X.; Liu, T.; Yu, J.; Li, L.; Feng, Y.; Li, X.; Food Chem. 2016, 197, 1184.

51. Rasheed, F.; Newson, W. R.; Plivelic, T. S.; Kuktaite, R.; Hedenqvist, M. S.; Gällstedt, M.; Johansson, E.; Int. J. Biol. Macromol. 2015, 79, 151.

52. Qiu, C.; Sun, W.; Su, G.; Cui, C.; Zhao, M.; J. Cereal Sci. 2014, 60, 143.

53. Jordens, S.; Adamcik, J.; Amar-Yuli, I.; Mezzenga, R.; Biomacromolecules 2011, 12, 187.

54. Geagea, H.; Gomaa, A. I.; Remondetto, G.; Moineau, S.; Subirade, M.; Int. J. Food Microbiol. 2015, 210, 33.

55. Kikhney, A. G.; Svergun, D. I.; FEBS Lett. 2015, 589, 2570.

56. Huang, C.; Wang, Y.; Gong, M.; Wang, W.; Mu, Y.; Hu, Z.-H.; Sep. Purif. Technol. 2020, 230, 115877.

57. Ataei, F.; Hosseinkhani, S.; J. Photochem. Photobiol., B 2015, $144,1$.

58. Liu, W.; Bratko, D.; Prausnitz, J. M.; Blanch, H. W.; Biophys. Chem. 2004, 107, 289.

59. Taboada, P.; Barbosa, S.; Castro, E.; Gutiérrez-Pichel, M.; Mosquera, V.; Chem. Phys. 2007, 340, 59.

60. Szymańska, A.; Hornowski, T.; Ślósarek, G.; Acta Biochim. Pol. 2012, 59, 317.

61. Herrera, M. G.; Veuthey, T. V.; Dodero, V. I.; Colloids Surf., $B$ 2016, $141,565$.

62. Joye, I. J.; Nelis, V. A.; McClements, D. J.; Food Hydrocolloids 2015, 44, 86.

63. Sotomayor-Gerding, D.; Oomah, B. D.; Acevedo, F.; Morales, E.; Bustamante, M.; Shene, C.; Rubilar, M.; Food Chem. 2016 , 199, 463.

64. Krejci, L.; Svedberg, T.; J. Am. Chem. Soc. 1935, 57, 946.

65. Chourpa, I.; Ducel, V.; Richard, J.; Dubois, P.; Boury, F.; Biomacromolecules 2006, 7, 2616.

66. Giugliarelli, A.; Paolantoni, M.; Morresi, A.; Sassi, P.; J. Phys. Chem. B 2012, 116, 13361.

67. Hansen, J.; Platten, F.; Wagner, D.; Egelhaaf, S. U.; Phys. Chem. Chem. Phys. 2016, 18, 10270.

68. Tjernberg, A.; Markova, N.; Griffiths, W. J.; Hallén, D.; J. Biomol. Screening 2005, 11, 131.

Submitted: July 27, 2020

Published online: November 10, 2020 